\title{
Simultaneous measurements from the Millstone Hill radar and the Active satellite during the SAID/SAR arc event of the March 1990 CEDAR storm
}

\author{
M. Förster ${ }^{1}$, J. C. Foster ${ }^{2}$, J. Smilauer ${ }^{3}$, K. Kudela ${ }^{4}$ and A. V. Mikhailov ${ }^{5}$ \\ ${ }^{1}$ GeoForschungsZentrum Potsdam, Germany \\ ${ }^{2}$ Massachusetts Institute of Technology, Westford, MA, USA \\ ${ }^{3}$ Institute of Atmospheric Physics, Prague, Czech Republic \\ ${ }^{4}$ Institute of Experimental Physics, Kosice, Slovak Republic \\ ${ }^{5}$ IZMIRAN, Russian Academy of Sciences, Troitsk, Russia
}

Received: 26 May 1998 / Revised: 19 August 1998/ Accepted: 24 August 1998

\begin{abstract}
During a nearby passage of the Active satellite above the Millstone Hill radar on 21 March 1990 at local sunset, the satellite and the radar performed simultaneous measurements of upper ionospheric parameters in nearly the same spatial volume. For this purpose the radar carried out a special azimuth-elevation scan to track the satellite. Direct comparisons of radar data and in situ satellite measurements have been carried out quite rarely. In this case, the coincidence of co-ordinated measurements and active ionospheric-magnetospheric processes during an extended storm recovery phase presents a unique occasion resulting in a very valuable data set. The measurements show generally good agreement both during quiet prestorm and storm conditions and the combination of radar and satellite observations gives a more comprehensive picture of the physical processes involved. We find a close relationship between the rapid westward ion drift peak at subauroral latitudes (SAID event) and the occurrence of a stable auroral red (SAR) arc observed after sunset by an all-sky imager and reported in an earlier study of this event. The SAID electric field is caused by the penetration of energetic ions with energies between about $1 \mathrm{keV}$ and $100 \mathrm{keV}$ into the outer plasmasphere to a latitude equatorward of the extent of the plasmasheet electrons. Charge separation results in the observed polarisation field and the SAID. Unusually high molecular ion densities measured by the satellite at altitudes of $700-870 \mathrm{~km}$ at subauroral and auroral latitudes point on strong upward-directed ion acceleration processes and an intense neutral gas upwelling. These structures are collocated with a narrow trough in electron density and an electron temperature peak as observed simultaneously by the radar and the satellite probes.
\end{abstract}

Key words. Ionosphere (ionosphere-magnetosphere interactions; plasma temperature and density). Magnetospheric physics (plasmasphere).

\section{Introduction}

The incoherent scatter radar facility at Millstone Hill, Westford, Massachusetts $\left(42.6^{\circ} \mathrm{N}, 288.5^{\circ} \mathrm{E}\right)$ used a fully steerable 46-m antenna to track the Active satellite which passed the station about $1000 \mathrm{~km}$ eastward during its descending branch of orbit 2174 on March 21,1990 , from about 22:21 UT to $22: 33$ UT. This was done in co-operation with and after former arrangement with Russian scientists from the Institute for Terrestrial Magnetism, Ionosphere and Radio Wave Propagation of the Russian Academy of Sciences (IZMIRAN) in Troitsk near Moscow who carried out a near-Earth space mission aimed on active plasma experiments within the frame of the East-European space research program (Intercosmos). Within that program, the mother-daughter pair of the Active satellite mission (Intercosmos-24) was launched on September 28, 1989.

Active and its subsatellite Magion-2 (Třiska et al., 1990) had a near-polar orbit in the upper ionosphere or near-Earth magnetosphere with an inclination of $82.5^{\circ}$, a revolution period of about $115 \mathrm{~min}$ and with apogee/ perigee altitudes of about 2500 and $500 \mathrm{~km}$, respectively. The main scientific objective of the mission was the performance of active experiments in the near-Earth space onboard the main satellite. So, during the interval of our interest an active experiment was performed between 22:21 UT and 22:29 UT. Narrow band $10 \mathrm{kHz}$ VLF waves were radiated with a power of a few hundred watts only. They were emitted in regular patterns of eight 64-s-cycles; each consisting of twelve 2-s-pulses. The effect of these pulses is mainly registered as transient and reversible steplike changes of the satellite potential. These short intervals have been excluded from the following data analysis.

Passive registrations of the upper ionospheric plasma parameters were continuously recorded by an onboard memory of the main satellite. Measurements from the ion mass spectrometer (HAM-5), the high-frequency

Correspondence to: M. Förster 
probe (KM-6) and the high energy particle spectrometer (SP-1) were used for this study. They will be briefly described in the next section and their data are then presented and analyzed in the subsequent sections. Measurements from another overflight above Millstone Hill prior to the storm (orbit 2125 on March 17) can be used as quiet time reference.

The simultaneous radar observations during the Active passage are a unique opportunity not only because of the rare occasions of direct comparisons between satellite and ground-based data but especially due to the fact that it obviously coincided with a subauroral ion drift (SAID) event during the extended recovery phase of an interesting storm interval which became one of the study objects of the Coupling, Energetics and Dynamics of Atmospheric Regions (CEDAR) initiative. Up to now, a large number of studies have been published for the complex investigation of this storm, beginning with the papers of, e.g., Buonsanto et al. (1992) and Förster et al. (1992). For more detailed information the reader is referred to the CEDAR Web site under http://hyperion. haystack.edu/css/cedar_storm_study.html.

SAID events were first discovered from Cosmos 184 satellite data and described as polarization jet phenomena (PJ) by Galperin et al. $(1973,1974)$. Now they are usually called SAID events after their rediscovery by Smiddy et al. (1977) and were observed by many different satellite missions as well as ground-based techniques as summarized, e.g., by Anderson et al. (1991) and Rodger et al. (1992). These events appear as narrow (usually 100-200 km wide) bands of supersonic $(\sim 1 \mathrm{~km} / \mathrm{s})$ westward convection which occur during the recovery phase of magnetic storms close to but inside the plasmapause L-shell. They have a duration of several UT hours and extend from the postmidnight to evening local time (Galperin et al., 1997).

The geophysical situation during this storm is illustrated in Fig. 1 with the AE-, Kp-, and Dst-indices. The major storm of this period started with a sudden storm commencement on 20 March 1990 at 22:43 UT while the observations during the satellite's passage (orbit 2174) which are summarised in Sect. 3 were taken roughly $24 \mathrm{~h}$ later during the extended recovery phase. This time interval near local sunset is just one and a half hours prior to optical observations of a stable auroral red (SAR) arc at the same location after sunset which is reported by Foster et al. (1994) to be in association with the SAID event.

In Sect. 4 we discuss the geophysical conditions during this event as observed by the simultaneous radar/ satellite observations and the question to what extent the SAID/SAR arc structures are persistent throughout both the time interval of the satellite passage and the later interval of radar and optical observations of Foster et al. (1994). Section 5 summarises the results.

\section{Instrumentation}

The Active main satellite had a three-axis stabilization (gyro- and gravitational) with the $z$-axis pointing toward
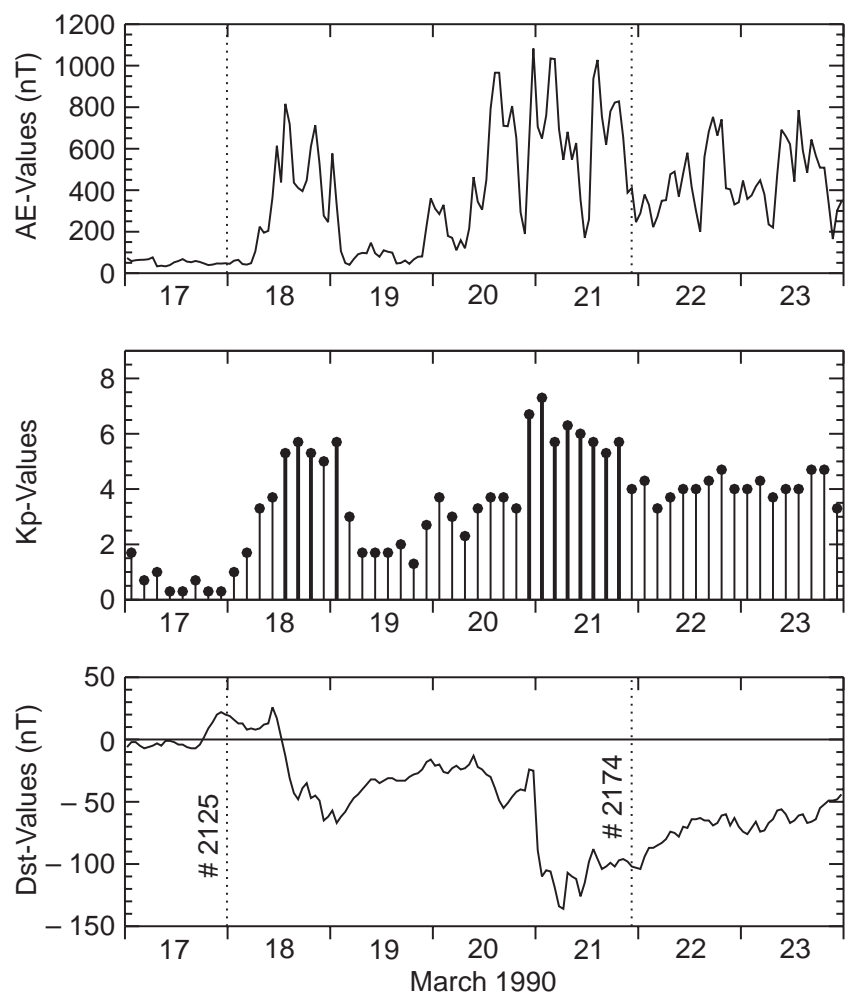

Fig. 1. Time variations of the geophysical indices AE, Kp, and Dst during the CEDAR storm of March 1990. The precise time of the Active overflights are indicated by dashed vertical lines

the zenith, the $x$-axis within the orbital plane toward the flight direction and the $y$-axis completes the rectangular satellite coordinate system. During the time interval of this study the orbital plane was in the morning-evening sector with the perigee above the equator at the evening side. The satellite's orbits under study here are declining in latitude and altitude above North America.

The ion mass spectrometer HAM-5 onboard the main satellite of the Active mission is a Bennett type radio-frequency analyser which determines the relative number density abundances for all ions in the upper ionosphere with a mass/charge ratio of 1 to 65 . The cold plasma probe KM- 6 , on the other hand, consists of a planar ion trap which is working as a retarding potential analyser (RPA) to obtain the total ion density and ion temperature as well as of three mutual perpendicular high frequency (HF) planar probes to measure three components of electron temperature. The total ion density measured by the planar ion trap of KM-6 serves for the absolute calibration of the sum of partial ion densities obtained by the HAM-5 probe. These two instruments have been developed at the Institute of Atmospheric Physics in Prague in a Czech-Russian cooperation with the Institute of Cosmical Research in Moscow. A detailed description of them can be found in Afonin et al. (1994). Some of the basic facts will be repeated here.

HAM-5 is a three-stage Bennett analyser with a linear ("current mode") amplifier. As the amplification factor of the output secondary emission amplifier varies 
with ambient temperature, it is necessary to calibrate the mass-spectrometric measurements to absolute values with the aid of RPA total ion concentrations measurements. The potential of the analyser was floating and controlled by the floating potential of an isolated electrode situated near the aperture of the ion mass spectrometer. The instrument had discrete ranges around the $\mathrm{m} / \mathrm{q}$ ratios $1,2,3$, and 4 and a continuous range from 6 to $64 \mathrm{amu}$ per elementary charge unit. All work with a constant accelerating voltage and a frequency sweep. So, concentrations of atomic ions $\mathrm{O}^{+}, \mathrm{N}^{+}, \mathrm{He}^{+}$, and $\mathrm{H}^{+}$were measured in the upper ionosphere as is shown, e.g., in Fig. 2 for a quiet time reference orbit 2125 which passed Millstone Hill just prior to the first storm onset a few minutes before midnight of March 17, 1990, within a horizontal distance of $160 \mathrm{~km}$. The direct comparison of electron density measurements onboard Active with the radar electron density profile in Fig. 3 shows an excellent agreement at the height of overflight at $720 \mathrm{~km}$ between these two independent data sets.

At lower altitudes or during geomagnetically disturbed conditions also molecular ions were registrated along the satellite's orbit. A rare occurrence of molecular ions at the mid-latitude upper ionosphere (around $720 \mathrm{~km}$ altitude) is one of the subjects of this study and will be discussed later (see Fig. 8). The instrument has a sensitivity threshold of about $5 \mathrm{~cm}^{-3}$. The mass resolution $M / \Delta M$ was about 25 for the $10 \%$ level. The time to measure one full spectrum of the ion densities with the telemetry rate used for this study is about $6 \mathrm{~s}$.

The cold plasma probe KM-6 had a planar ion trap along the velocity vector, which operated in RPA mode (about $2 \mathrm{~s}$ sweep and $2 \mathrm{~s}$ on plasma potential) or in

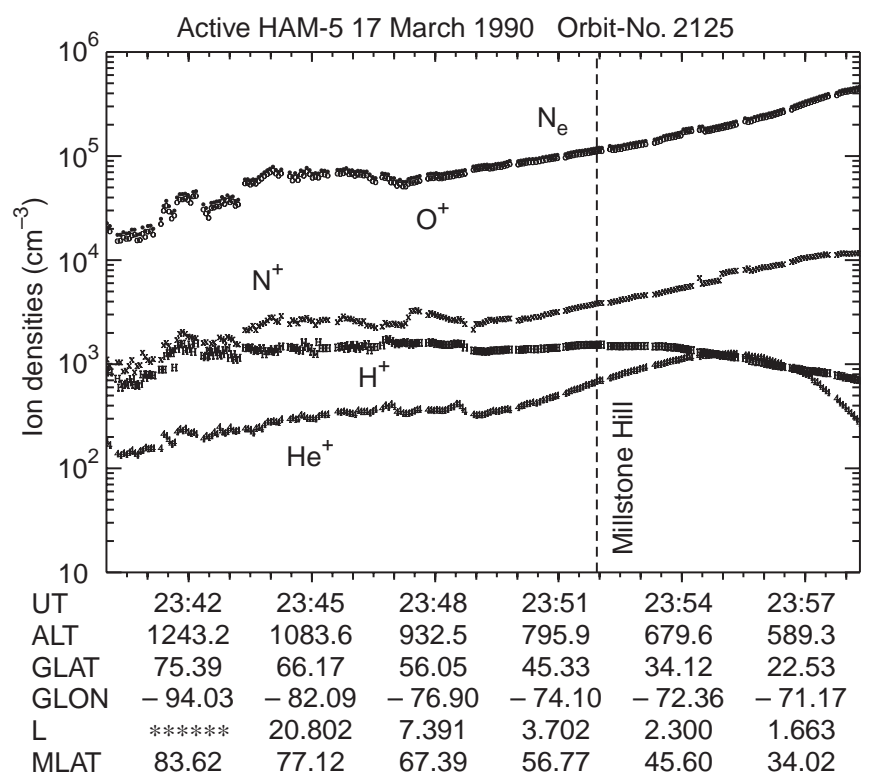

Fig. 2. Ion density measurements of the HAM-5 probe onboard the Active satellite along the orbit 2125 path. This passed the Millstone Hill station within a horizontal distance of the path projection to the Earth's surface of $160 \mathrm{~km}$ just prior to the first storm onset during local sunset (23:52 UT) on 17 March 1990. See Fig. 3 for the direct comparison with the radar measurements

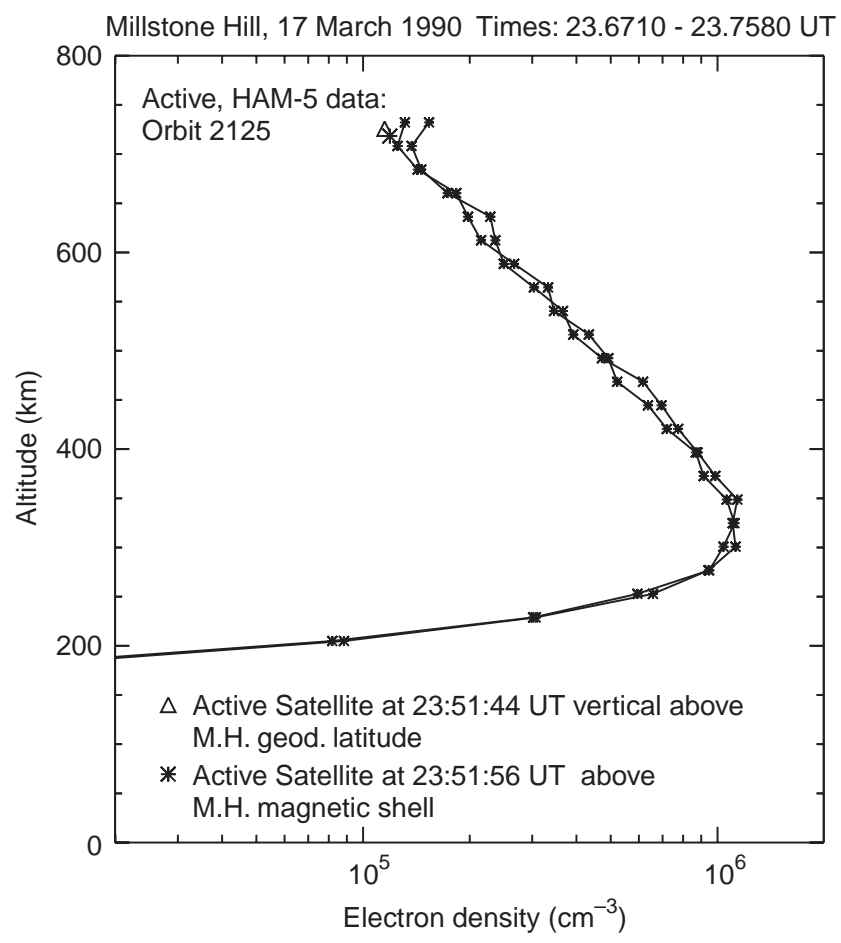

Fig. 3. Direct comparison of electron density measurements of the HAM-5 probe onboard the Active satellite with the measured Millstone Hill $N_{e}$ radar profile for the direct overflight during orbit 2125 on March 17, 1990, a geomagnetically quiet prestorm day

continuous mode, measuring summary ion concentration only. Further the probe contains three mutually perpendicular planar high-frequency probes to measure all components of the electron temperature. They are bound to the satellite co-ordinate system, not to geomagnetic coordinates. In this study the components $T_{e z}$ toward the zenith and $T_{e y}$ in the horizontal direction perpendicular to the orbital plane are used. At high latitudes, the first is nearly field-aligned while the latter represents approximately the magnetic field-perpendicular component. The $T_{e x}$ measurement is designed for ion concentrations smaller than about $3 \times 10^{5} \mathrm{~cm}^{-3}$. It is incorrect for larger densities due to a very thin Debyelayer and the high capacity of the electrode against the surrounding plasma. The electron temperature is calculated from changes of the probe potential while a HF voltage is superimposed (Smilauer and Kubat, 1973). The frequency used was about $50 \mathrm{kHz}$, far from all plasma resonances for near-Earth space conditions. The calculations are based on the assumption of a MaxwellBoltzmann distribution. The overall period of $\mathrm{HF}$ voltage superimposed was $50 \mathrm{~ms}$, the resolution of about $80 \mathrm{~ms}$ is due to the telemetry rate used. Finally, the KM-6 device also contains a probe for floating potential measurements.

The spectrometer of energetic protons and electrons (SPE-1) was developed and built at the Institute of Experimental Physics in Kosice (Slovak Republic) in cooperation with specialists from the Institute of Cosmic Research in Moscow (Russia). Energetic particle fluxes were measured by the use of single silicon surface barrier 
detectors. The SPE-1 instrument consists of three pairs of such detectors for the spectral and angular resolution of protons and electrons in the energy range of ring current particles of tens to hundreds of $\mathrm{keV}$. The electron detectors were covered by Mylar foils stopping protons up to $700 \mathrm{keV}$ while the proton detectors had magnetic filters which rejected electrons up to $650 \mathrm{keV}$. The middle proton detector (number 2) was additionally protected by a thin foil against incidence of direct or reflected sunlight. The latter proved to be a lucky chance especially for the orbit investigated in this study because the two other proton detectors were saturated by solar irradiance due to unfavourable satellite attitude during this interval.

The energy ranges are slightly different for each detector owing to their individual characteristics. They were calibrated individually prior to the launch of the satellite. Three different modes of spectral resolution were possible: 7, 15 or 31 quasi-logarithmically distributed energy channels. A lower spectral resolution allowed a higher temporal resolution and vice versa. The energy channels covered an interval of about $20-450 \mathrm{keV}$ for the three electron detectors and 55-524 keV for the second proton detector. They are regularly distributed in the logarithmic energy space except of the uppermost energy channel of the first mode. This channel had a threshold that led to sampling of particles not only from its energy interval but also from some higher range of energy. Therefore, we did not include data of this energy channel into our false-colour spectral plots.

The temporal resolution depended also from the telemetry mode selected. For this study we used data recorded by the on-board memory regime which were transmitted later to the ground station. During the orbit 2174 the lowest energy resolution (7 energy channels) was switched on and together with a medium telemetry rate it resulted in a temporal resolution of $0.32 \mathrm{~s}$. The full acceptance angle of the detectors is $20^{\circ}$ and their angular orientation is $30^{\circ}$ apart for each particular pair to obtain some pitch angle resolution of the particle fluxes. The geometrical factor of the detectors is $0.03 \mathrm{~cm}^{2} \mathrm{sr}$. For a more detailed description of the SPE-1 instrument the reader is referred to the paper of Kudela et al. (1992).

The Defense Meteorological Satellite Program (DMSP) satellite F8 is in a sun-synchronous polar circular orbit at about $830 \mathrm{~km}$ altitude and an orbital period of about $101 \mathrm{~min}$. Therefore, the satellite has an inclination of about $99^{\circ}$ and monitor the upper ionospheric parameters in a fixed local time plane. For the F8 satellite, it is approximately the dawn-dusk plane at about $06 \mathrm{LT}$ and $18 \mathrm{LT}$ with respect to the equatorial crossings. During the time interval of the event under study, the F8 satellite performed latitudinal cuts across the northern auroral and subauroral latitudes along descending branches of its orbit near Millstone Hill between 19 MLT and 21 MLT.

The satellite provides high-resolution in situ observations of the vertical and horizontal plasma drifts (perpendicular to the satellite's velocity vector), thermal summary ion densities as well as precipitating supra- thermal electron and ion fluxes over the energy range of $30 \mathrm{eV}$ to $30 \mathrm{keV}$. The energetic particle spectra were obtained in twenty energy channels with a time resolution of $1 \mathrm{~s}$ (about $8 \mathrm{~km}$ spatial resolution). The drift meter velocities have a resolution of $1 / 6 \mathrm{~s}$ (about $1 \mathrm{~km}$ ) and the density measurements, finally, $1 / 24 \mathrm{~s}(0.32 \mathrm{~km})$. These instruments have been described in more detail in the papers of Green et al. (1986) and Richards et al. (1994).

The Millstone Hill radar is located in eastern Massachusetts at $42.6^{\circ} \mathrm{N}$ and $288.5^{\circ} \mathrm{E}$ geodetic coordinates, i.e. at $54.1^{\circ}$ geomagnetic or $54.8^{\circ}$ invariant latitude (McIlwain parameter $L=3.0$ ). It is therefore well situated for magnetosphere-ionosphere coupling studies near the projection of the plasmapause, i.e. near the storm time inner edge of plasmasheet particle injection, the ring current intensification, and the ionospheric main trough to list here only a few 'hot topics' of current investigations. The radar beam can routinely gather data from a wide range of latitudes between about $36^{\circ}$ and $75^{\circ}$ of invariant latitude. The Millstone Hill UHF incoherent scatter radar monitors ionospheric parameters, as there are mainly the electron density $N_{e}$, electron and ion temperatures $T_{e, i}$, and the line-of-sight bulk plasma drift velocity $V_{i}^{\text {l.o.s. }}$. By combining different aspect angles it is possible to derive also the full vector of the large-scale plasma drift, but with a much poorer time resolution only. A typical altitude or spatial resolution is $50 \mathrm{~km}$ while the data can be obtained over an altitude range of $150 \mathrm{~km}$ to $1000 \mathrm{~km}$, dependent on the power of the backscattered signal. For low-elevation observations the fully steerable 46-m antenna allows to gather data from distances as far as $2000 \mathrm{~km}$ or $30^{\circ}$ in longitude to each side.

\section{Observations}

\subsection{The radar's azimuth-elevation scan}

For this study, a special azimuth-elevation Millstone Hill radar scan was performed which started at very low elevations toward geographic north, achieved highest elevation with $30^{\circ}$ at an azimuth of about $70^{\circ}$ and returned to low elevations toward geographic south-east $\left(137^{\circ}\right)$. This was done to track the satellite pass of Active, orbit 2174, on March 21, 1990. The tracking can be resolved in 46 individual radar positions with integration times of $10 \mathrm{~s}$ each. The pass is illustrated in a geographic latitude-longitude plot (Fig. 4) together with the ion temperature measurements of the azimuthelevation radar scan. Owing to the geometry of the radar beam the data points nearer to the station are taken at lower altitudes than the points further away. The time marks along the satellite trace are given in UT hours and minutes. During its descending orbit the satellite came down in height and entered the radar's observational range near 22:24 UT. At 22:26 UT it crossed a longitudinally extended discrete auroral arc seen as a band of highly enhanced ion temperature near $53^{\circ}$ geographic latitude. Another small region of highly 
Active, 21 March 1990, Orbit 2174

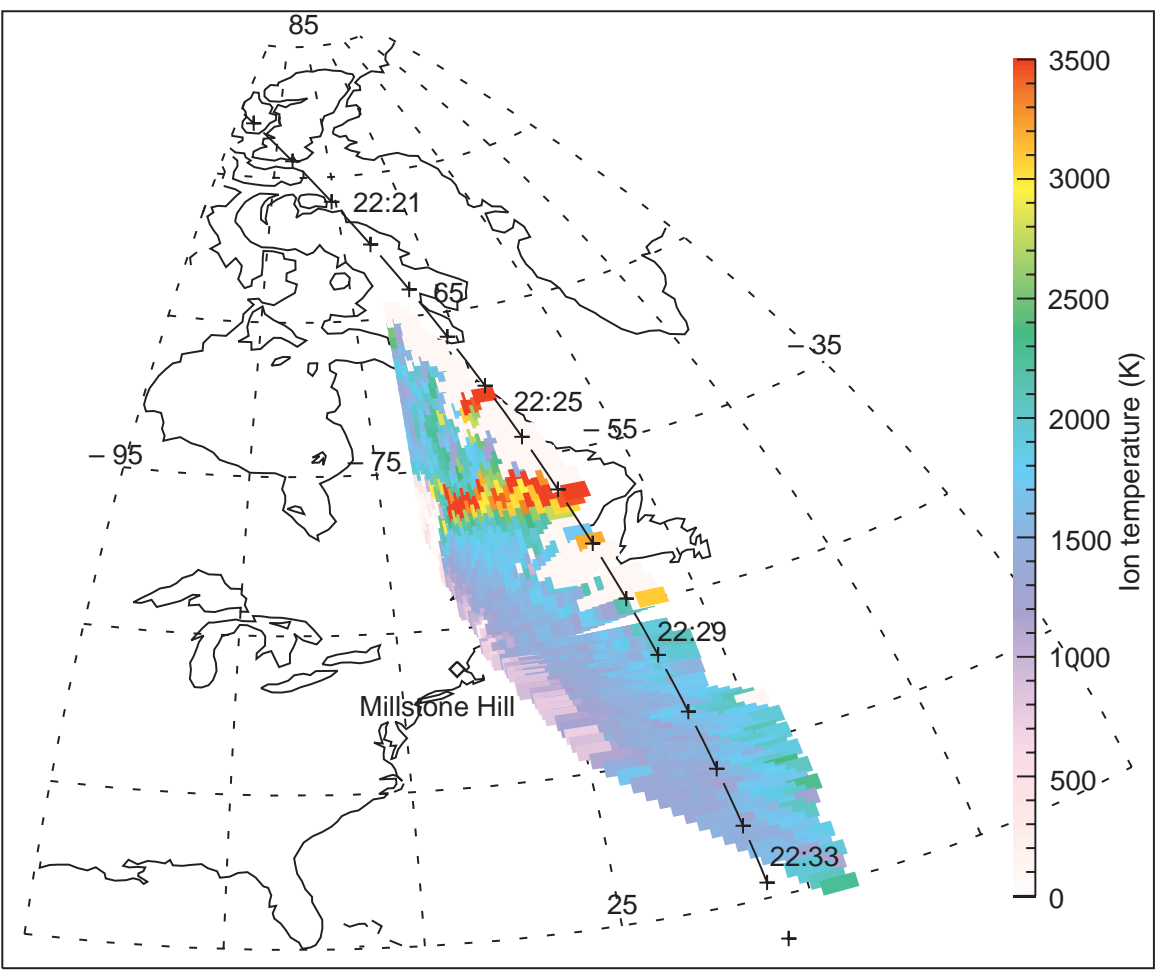

Fig. 4. The descending orbit 2174 of the Active main satellite on March 21, 1990, during its passage $\mathrm{E}$ of the Millstone Hill incoherent scatter radar station (location indicated by diamond). The ion temperature measurements of the simultaneous azimuth-elevation-scan of the radar are shown in geographic latitude and longitude coordinates. According to the beam geometry they represent different altitudes enhanced ion temperature is seen further north near $59^{\circ}$ at high altitudes only. At all other latitudes the ion temperature profile is characterised by a smooth increase from about $1000 \mathrm{~K}$ near $200 \mathrm{~km}$ to about $2000 \mathrm{~K}$ at the largest altitudes (distances) of the radar reach. White bins indicate the failure of signal evaluation due to low backscattered power as at high altitudes northward from Millstone Hill or due to plasma turbulence as at $200 \mathrm{~km}$ altitude near the auroral arc.

Figure 5 shows the radar measurements during the same satellite overflight as colour-coded plots in altitude versus geomagnetic latitude frames. The ion temperature enhancement is seen here as a thin field-aligned structure near $64^{\circ}$ geomagnetic latitude and a further enhancement near $70^{\circ}$ at high altitudes only (upper left panel) while $T_{e}$ (upper right) has elevated values over a much wider range down to the latitude of Millstone Hill. As was already the case for the $T_{i}$, the $T_{e}$ plot also shows some areas in the auroral and subauroral upper ionosphere with data gaps (white bins) due to poor backscattered radar signals which do not allow the temperature estimation.

It is obvious, however, that there are two different regions of $T_{e}$ enhancement: one near the auroral arc extending northward and an other at subauroral latitudes around $57^{\circ}$ geomagnetic latitude or 22:28 UT of the satellite passage. While the former region is characterised by strongly enhanced $T_{i}$ and similar high $T_{e}$ values, the latter subauroral region has only elevated electron temperatures in the upper ionosphere. The ion temperature values there, however, are comparable to those in the adjacent mid-latitude region (compare the two upper panels of Fig. 5).
The auroral arc heating is mainly caused by the large Joule heating due to extremly strong drift velocities of the ions through the neutral gas (see Sect. 3.3 below). The heating of the electrons proceeds then via the elevated ion temperature although other heat sources cannot be excluded. At the subauroral heating region, in contrary, a different heating process dominates which is mainly effective for the thermal electrons. This heating stems obviously from a source region above the $F_{2}$-layer. The energy transfer to the ions via Joule heating near the subauroral drift maximum seems to be of minor importance, at least at this particular moment during the event under study.

\subsection{Simultaneous satellite in-situ measurements}

The $T_{e}$ observations are confirmed by the in situ measurements with the floating radio frequency probe KM-6 onboard Active which is shown in Fig. 6. The $T_{e}$ components vertical upward $\left(T_{e z}\right)$ and in horizontal direction $\left(T_{e y}\right)$ differ regularly by about $750 \mathrm{~K}$ within the region of overflight indicating an anisotropy with larger values in field-parallel direction. There are two outstanding $T_{e}$ peaks, one at 22:28 UT $\left(56.6^{\circ}\right.$ magnetic latitude) and the other at 22:26 UT $\left(64.1^{\circ}\right)$, with large dispersions. These peaks are present in both components, but the field-aligned temperature achieves larger values for both peaks (about $7200 \mathrm{~K}$ and $8500 \mathrm{~K}$, respectively) than the perpendicular one $(5400 \mathrm{~K}$ and $7000 \mathrm{~K}$ ). The averaged temperatures in the interval from 22:24 UT to $22: 29$ UT are about $1000-1500 \mathrm{~K}$ above the reference prestorm values of orbit 2125 (not shown 

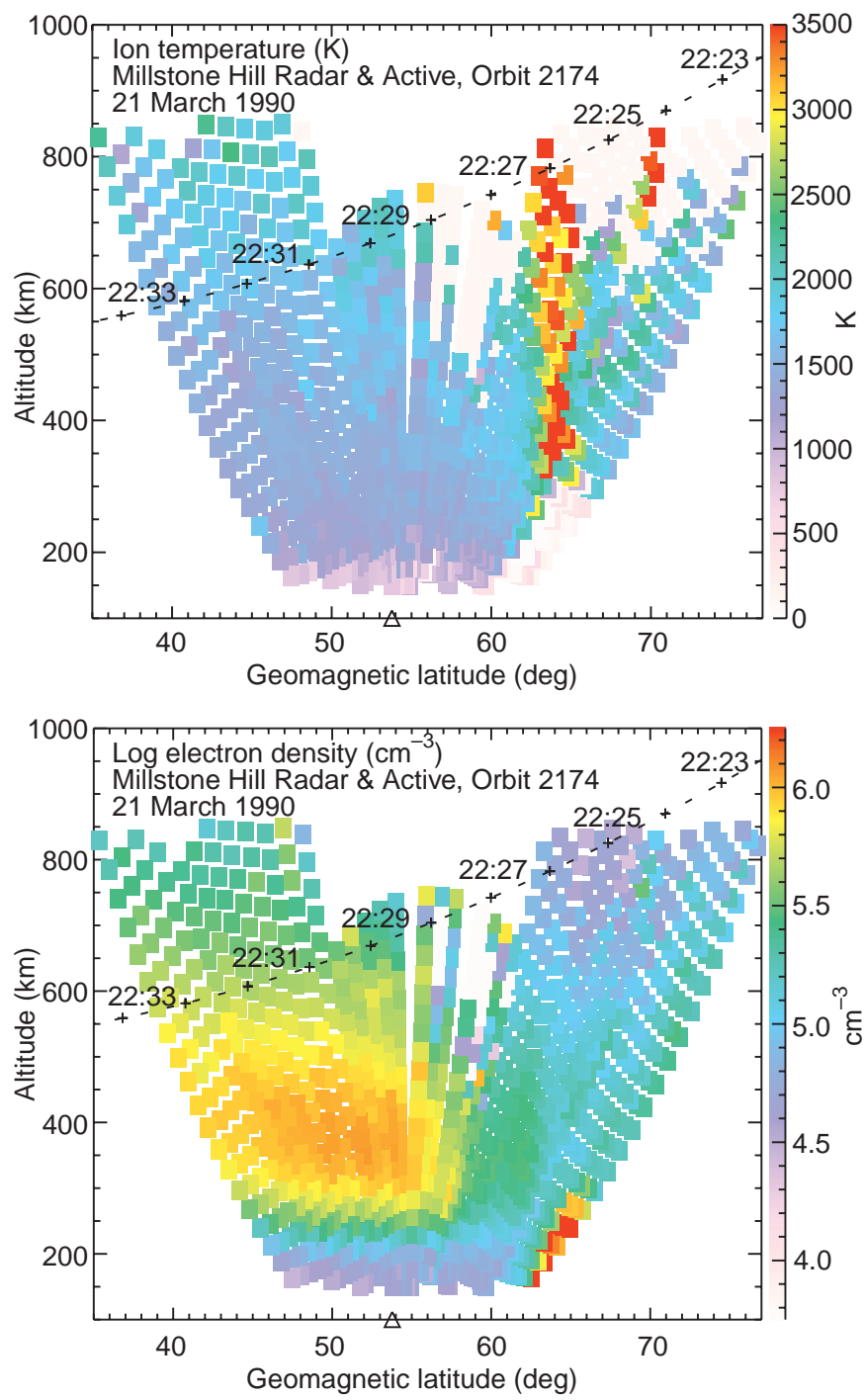

Fig. 5 a-d. The same pass of the Active satellite as in Fig. 4, but as altitude versus geomagnetic latitude colour-coded plots showing the simultaneously measured Millstone Hill radar data of the: $\mathbf{a}$ ion and $\mathbf{b}$ electron temperatures, $\mathbf{c}$ electron density and $\mathbf{d}$ the line-of-sight

here) for the same latitude interval and for both components.

The crossing of the $L$-shell of Millstone Hill is indicated by a dashed vertical line. From there onward to lower latitudes the $T_{e}$ values become smoother, drop down to about $2000 \mathrm{~K}$ and both components approach each other. In this latitudinal interval the $T_{e}$ amplitudes for both components are very similar to the prestorm reference orbit 2125 (not shown). Prior to 22:18:15 UT $T_{e y}$ dominates the $T_{e z}$ component. It starts at the left border of Fig. 6 when the satellite is near $79^{\circ}$ geomagnetic latitude in the prenoon sector $(\approx 08$ MLT $)$ and reaches $85.5^{\circ}$ near $12 \mathrm{MLT}$. This is probably related to the cusp region and is outside the scope of the present work.

The quite different nature of the two heating regions (as mentioned before in Sect. 3.1) can be elucidated by looking at the SPE-1 measurements of energetic electrons and ions of ring current particle energy along the
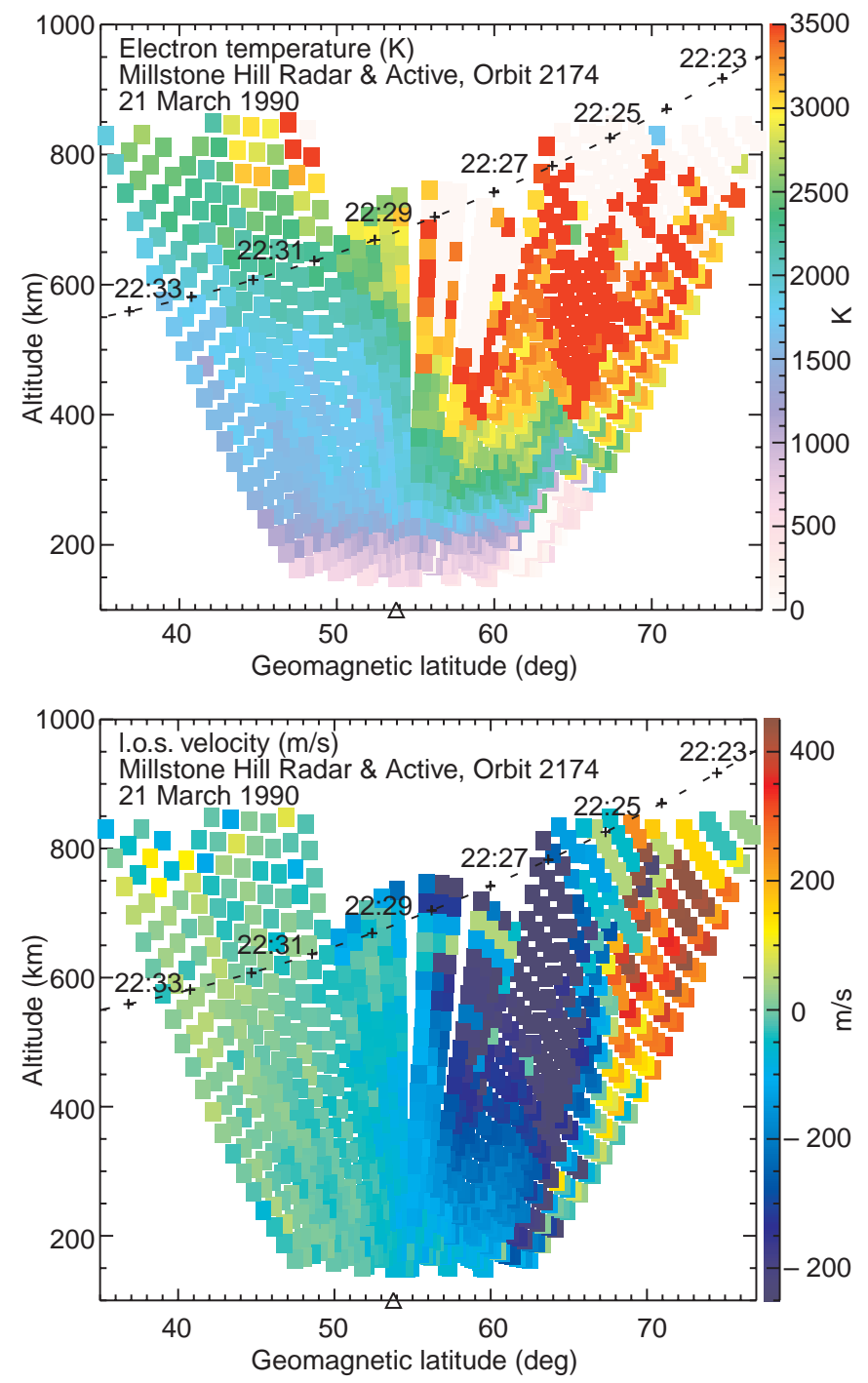

velocity. The satellite path is indicated by a dotted line with time marks; the plot represents different longitudes according to the beam geometry. A triangle on the base of the plot indicates Millstone Hill location

satellite track in Fig. 7. Depending on the detector they comprise an energy range between about 20 and $300 \mathrm{keV}$. Detector 2 for both electrons and ions (second and bottom panel of Fig. 7) is nearly field-perpendicular directed and shows freshly injected particles of the outer radiation belt. These particles can be regarded as "trapped" at $L$-shells between $L=5.0$ for ions or $L=4.6$ for electrons down to $L \approx 3.1$ or 2.6 , respectively.

Detectors 1 and 3 available for electrons only have observed precipitating and backscattered particles. These fluxes are less intense and show a "spiky" character, i.e., some intense isolated bursts at a continuous background between 22:26:30 UT and 22:28:30 UT are seen extending with some faint spikes till 22:29:30 UT or $L=2.6$ ( $51^{\circ}$ magnetic latitude).

Besides the difference in the latitude range there are significant differences in the spectral shape of the ion and electron "trapped" particle population (detectors $2)$. The ions reveal a characteristic energy dispersion 


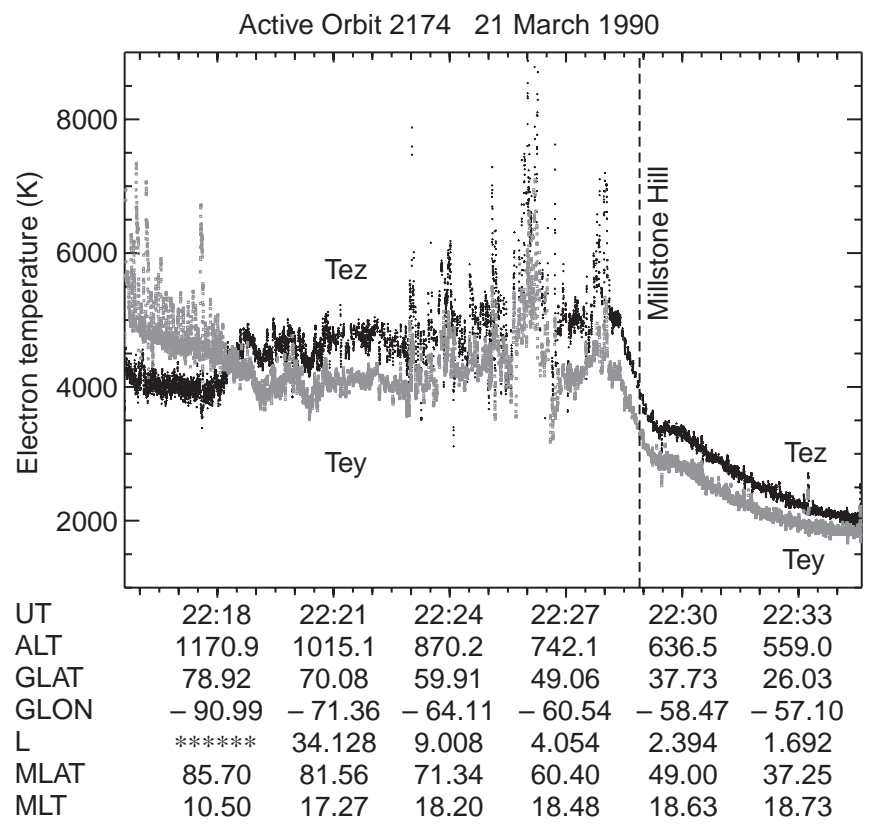

Fig. 6. Electron temperature measurements of the high frequency probe KM-6 along orbit 2174 of the Active main satellite on March 21, 1990 during its passage near the Millstone Hill station. $T_{e z}$ is the temperature component measured vertically upward; $T_{e y}$ is measured horizontally and perpendicular to the flight direction

with highest particle energies near 22:27 UT or $L \approx 4.2$ and the poleward boundary of the energetic ion flux coincides with the occurrence of the auroral arc (see Fig. 5 , upper left panel) or the poleward electron temperature peak (Fig. 6) at 22:26 UT (64.1 ${ }^{\circ}$ magnetic latitude). The "trapped" electrons coincide very well, on the other hand, with the enhanced temperature region at lower, subauroral latitudes and the most intense spikes seen by detectors 1 and 3 near 22:28 UT with the electron temperature maximum of that region.

At higher latitudes near 22:23 UT there is another, weaker electron precipitation region with energies of a few tens of $\mathrm{keV}$. This is just at the poleward edge of the auroral heating region.

Let us return to Fig. 5. The lower left panel shows the electron density height profiles versus geomagnetic latitude while the lower right panel illustrates the lineof-sight ion drift velocity of the radar observations. Contrary to the well-formed $F_{2}$-layer above and southward of Millstone Hill, the auroral and subauroral regions exhibit large plasma density depletions coinciding with enhanced plasma drifts toward the radar at subauroral and auroral latitudes smaller than about $66^{\circ}$ geomagnetic latitude or away from it at higher latitudes. At subauroral latitudes and altitudes above about $500 \mathrm{~km}$ the $N_{e}$ depletion leads to larger data gaps due to insufficient backscatter power. The point of very large $N_{e}$ densities at the bottom of the auroral arc field line around $200 \mathrm{~km}$ altitude and $64^{\circ}$ must be related to additional ionization by precipitating particles.

Figure 8 reveals ion composition details in the upper ionosphere along the satellite track from the HAM-5 measurements on board Active. The dominating ion is atomic oxygen, but $\mathrm{N}^{+}, \mathrm{He}^{+}$, and protons were also registered in the upper ionosphere as it was the case for the quiet time reference orbit (Fig. 2) with nearly the same orbital parameters. However, within the time interval of the auroral and subauroral regions overflight between 22:24 UT and 22:28 UT, enhanced molecular ion density peaks of $\mathrm{NO}^{+}, \mathrm{N}_{2}^{+}$, and $\mathrm{O}_{2}^{+}$are observed at altitudes between $700-870 \mathrm{~km}$ with density peaks of about $1.5 \times 10^{2} \mathrm{~cm}^{-3}$.

This is quite unusual and points to strong ion acceleration processes (heating) within these two regions, accompanied by a factor of three $N_{e}$ density depletions. This trough has a sharp equatorial boundary at $56^{\circ}$ geomagnetic latitude starting with an abrupt (factor two or more) decrease in $N_{e}$ while the poleward flank rises gradually. One has to bear in mind that there is a background decline of plasma density with increasing latitude due to the increasing altitude of the satellite in accordance with the plasma scale height. At high latitudes prior to 22:18:15 UT another trough region is seen. As stated before, this is presumably due to the polar cusp.

The dominating molecular ion within the subauroral trough is $\mathrm{N}_{2}^{+}$while within the more northward part of the upwelling which is collocated with the auroral $\operatorname{arc}(\mathrm{s})$ $\mathrm{NO}^{+}$and $\mathrm{N}_{2}^{+}$contribute equally to the peaks. $\mathrm{O}_{2}^{+}$is also present there but with much lower abundance. It is clear that the standard ion composition profile for the radar routines is not applicable here, but according to rough estimations this concerns mainly the radar profiles of $T_{e}$ and $T_{i}$ below about $400-500 \mathrm{~km}$ altitude. Their corrections should be made as proposed, e.g., by Mikhailov and Schlegel (1997). On the other hand, we are mainly interested in the measured radar data above this height in the upper ionosphere where we have the direct comparison with the satellite data.

The direct comparison of radar observations of electron density and temperature and satellite measurements shows a good agreement at lower and middle latitudes (outside the disturbed regions). Figure 9 shows the binned satellite measurements $\left(1^{\circ}\right.$-wide bins and standard deviations indicated by vertical lines) versus magnetic latitude together with, if available, the nearest (in altitude) radar observational points for each time moment. The differences between radar and satellite measurements are of the order of $10-20 \%$ for $N_{e}$ at geomagnetic latitudes $<43^{\circ}$ and about $50 \%$ at higher latitudes within and southward of the subauroral trough (upper left panel). One should keep in mind that the radar observations at high altitudes $(>600 \mathrm{~km}$, see upper right panel) are obtained at great distances and within a region of reduced density (backscatter power) and plasma disturbances. The artificially high density data points $\left(>3 \times 10^{5} \mathrm{~cm}^{-3}\right)$ obtained slightly northward of the radar station (its position is indicated by a triangle at the bottom) are possibly contaminated by interference.

The determination of accurate electron temperatures at altitudes $>600 \mathrm{~km}$ in a region of low plasma concentration is difficult as well and the results are susceptible 


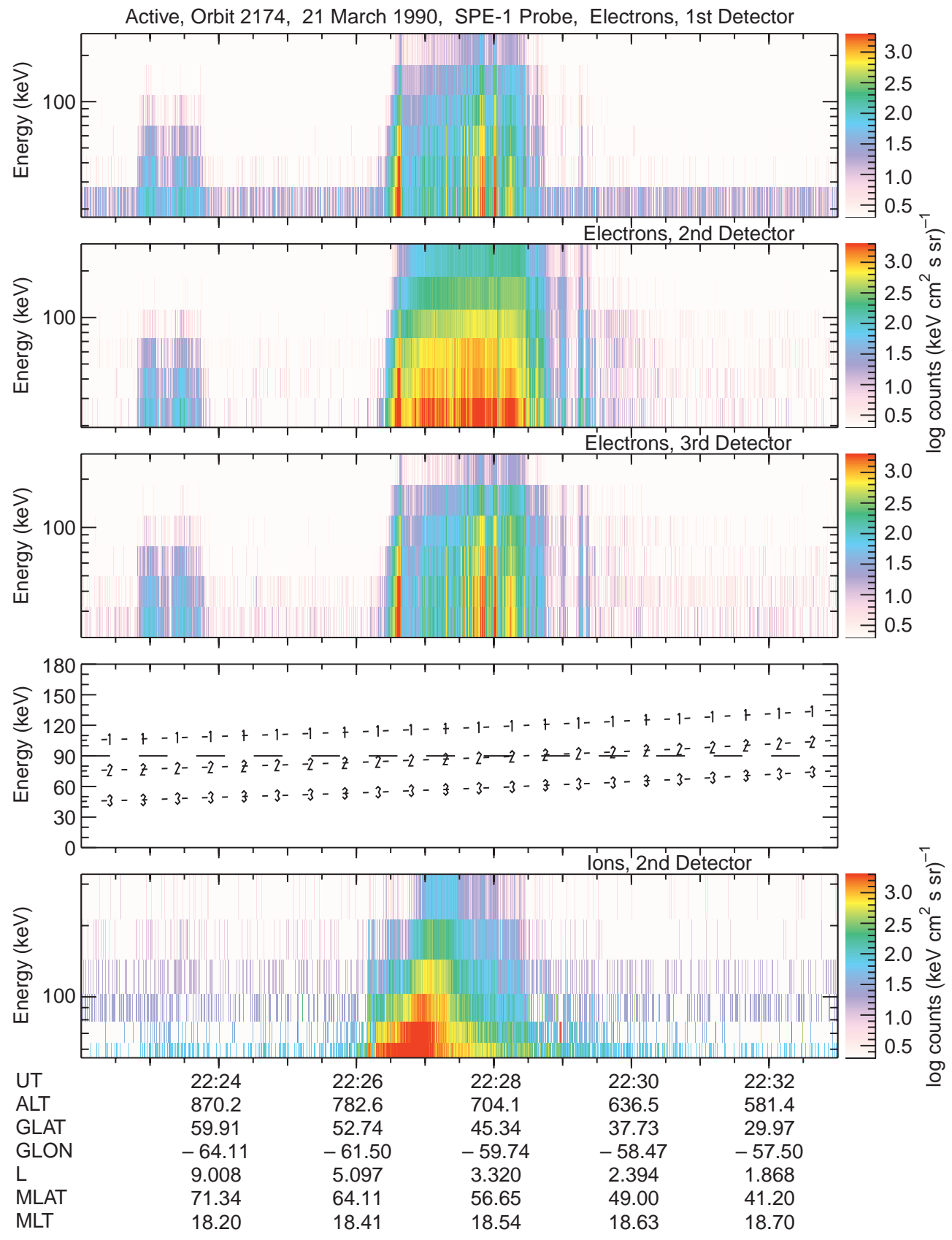

Fig. 7. SPE-1 energetic electron (upper three panels) and ion (bottom) spectra measured with three different detectors whose pitch angle orientations are given in the fourth panel. At the abscissa are shown the satellite's altitude $(A L T)$, geographic latitude $(G L A T)$ and longitude $(G L O N)$, the $L$-value, geomagnetic latitude $(M L A T)$ and the magnetic local time in decimal hours (MLT) to interference effects. The $T_{e y}$ component of the satellite data however shows a remarkably good (better than $20 \%$ ) agreement with the radar $T_{e}$ measurements at middle latitudes which are slightly (200-400 K) smaller (bottom left panel of Fig. 9). $T_{e z}$ (middle left panel), on the other hand, is systematically $(500-1000 \mathrm{~K})$ higher as reported before with regard to Fig. 6. The tendency of the radar measurements to follow more closely the $T_{e y}$ component of the satellite registrations could be explained by the aspect angle of the radar beam with respect to the geomagnetic field lines. Owing to the low elevation of the eastward pointing radar beam in the latitudinal range considered this angle is near $90^{\circ}$. Therefore the radar beam geometry obviously favours the extraction of the field-perpendicular component.
At higher latitudes a direct comparison of radar and satellite measurements is not possible due to the data gaps and the higher altitude of the satellite.

\subsection{Drift velocity estimations}

The Millstone Hill radar line-of-sight drift velocity measurements is presented already in the lower right panel of Fig. 5. For a better visualisation of the drift amplitudes Fig. 10 presents a latitudinal profile of the drift obtained by the radar azimuth-elevation scan at altitudes between $400 \mathrm{~km}$ and $500 \mathrm{~km}$. The westward drift velocity maximum of about $700 \mathrm{~m} / \mathrm{s}$ is observed near $64^{\circ}$ geomagnetic latitude, i.e. at the location of the 


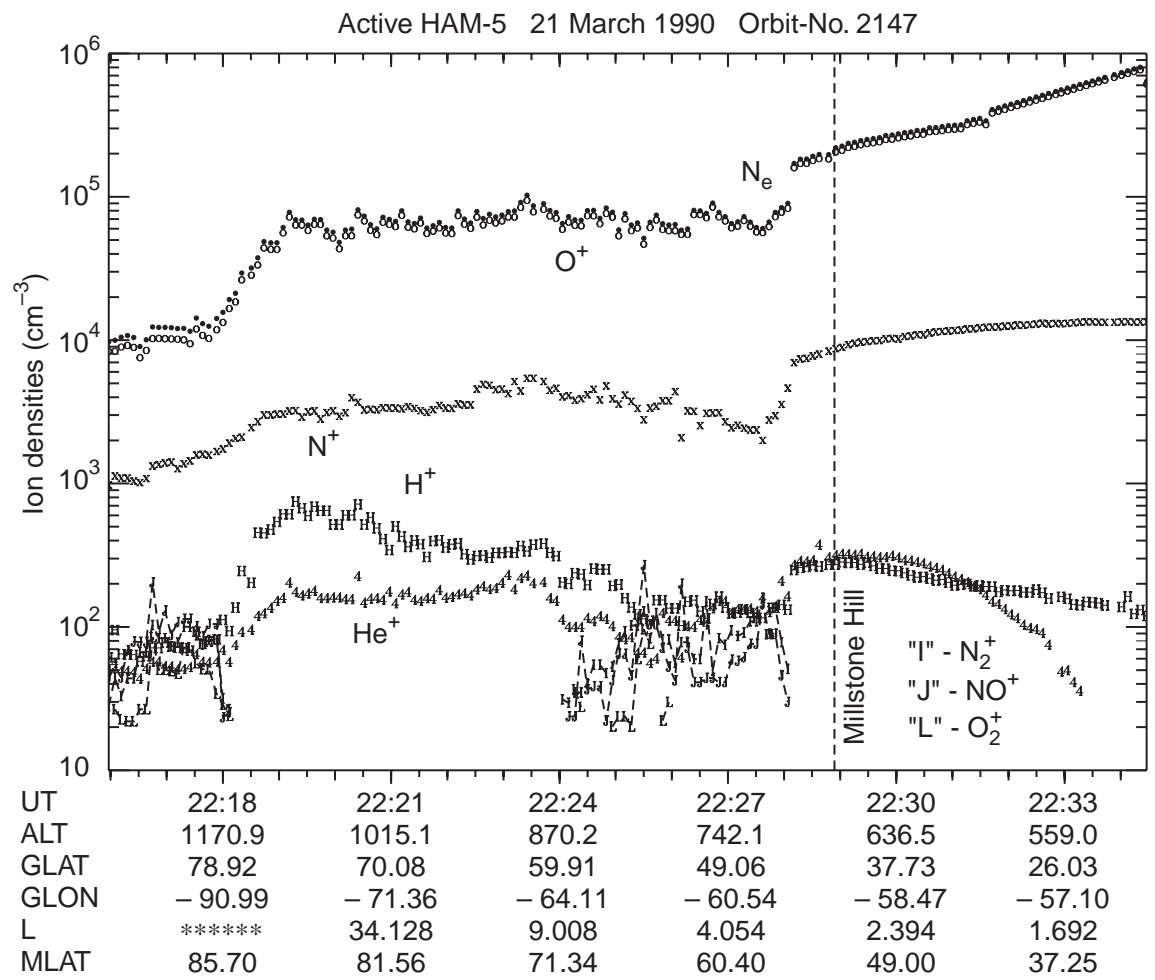

Fig. 8. HAM-5 ion spectrometer measurements along orbit 2174 of the Active main satellite on March 21, 1990, during its passage near the Millstone Hill incoherent scatter radar station. The ion densities are plotted versus UT. The satellite's position along the orbital track is given below as altitude, geographic latitude and longitude, the Mc'Ilwain parameter and the local solar time. The crossing of the Millstone Hill $L$ value shell is indicated by a vertical dashed line geomagnetic field line with maximal ion temperatures which was related to an auroral arc (see Figs. 4, 5 and 6). A secondary maximum of about $450 \mathrm{~m} / \mathrm{s}$ westward directed drift velocity is observed around $58^{\circ}-59^{\circ}$ geomagnetic latitude in the subauroral region, approximately collocated with the $T_{e}$ maximum in that region (Fig. 6). It should be remembered that the radar observes only line-of-sight velocities, i.e. the projection of the full velocity vector with respect to the station's view direction in azimuth and elevation. Assuming a strict east-west (longitudinal) drift, this aspect angle is about $75^{\circ}$ for the main drift maximum and $50^{\circ}$ for the secondary maximum, so that the true amplitudes of the drift maxima would be larger by a factor of 3.86 and 1.56 , respectively. This rough estimation results in drift velocities of about $2700 \mathrm{~m} / \mathrm{s}$ for the main peak and $700 \mathrm{~m} / \mathrm{s}$ for the secondary peak.

To check the plasma drift situation we made use of the drift pattern estimated with the Assimilative Mapping of Ionospheric Electrodynamics (AMIE) procedure (Richmond and Kamide, 1988; Richmond, 1992) which was applied to the March 1990 CEDAR storm period by Taylor et al. (1994, 1996). We projected the potential distribution of the nearest time moment (22:25 UT) into the geographic coordinate system together with the plots of the radar drift measurements (Fig. 11a) and of the ion temperature (Fig. 11b) which was shown already in Fig. 4. The AMIE contours are drawn with $8 \mathrm{kV}$ spacings with red isolines for negative potential values and the green line as the zero potential. The drift pattern shows a large convection cell northeast of the Millstone Hill radar station.

The northward-directed electric field just northeastward of the radar is equivalent to an westward drift which is also observed by the radar as a drift component toward the facility. The dense bundle of contour lines at a distance of about $1200 \mathrm{~km}$ northeast of Millstone Hill indicates a very intense westward drift jet. The drift can be estimated from the contour distance to about $2 \mathrm{~km} / \mathrm{s}$ within the view range of the radar. This is colocated with the auroral arc seen as an ion temperature enhancement near $53^{\circ}$ geographic latitude (Fig. 11b). The westward drift jet has a slight northward component, i.e. it is directed toward an azimuth of about $285^{\circ}-290^{\circ}$. Therefore, the aspect angles should be corrected again which leads to even larger correction factors for the drifts which leads, e.g., for the SAID peak to an amplitude of about $1000 \mathrm{~m} / \mathrm{s}$.

Further north at about $58^{\circ}$ geographic latitude a drift shear region is present which is also seen by the radar as a turning of the line-of-sight velocity away from Millstone Hill (Fig. 11a) and as an other "hot spot" in $T_{i}$ (Fig. 11b). The accuracy of the AMIE method depends mainly on the mean distance of magnetic ground stations involved in the potential estimations. This is of the order of $100 \mathrm{~km}$, i.e., fine structures of the drift cannot be resolved adequately. Nevertheless, the correspondence of the AMIE drift pattern with the radar measurements is surprisingly good.

\section{Discussion}

The simultaneous radar and satellite observations complement each other and give a comprehensive picture of the physical situation at the end of larger geomagnetic storm forcings during this extended recovery phase (Fig. 1). The direct comparison of the data, 


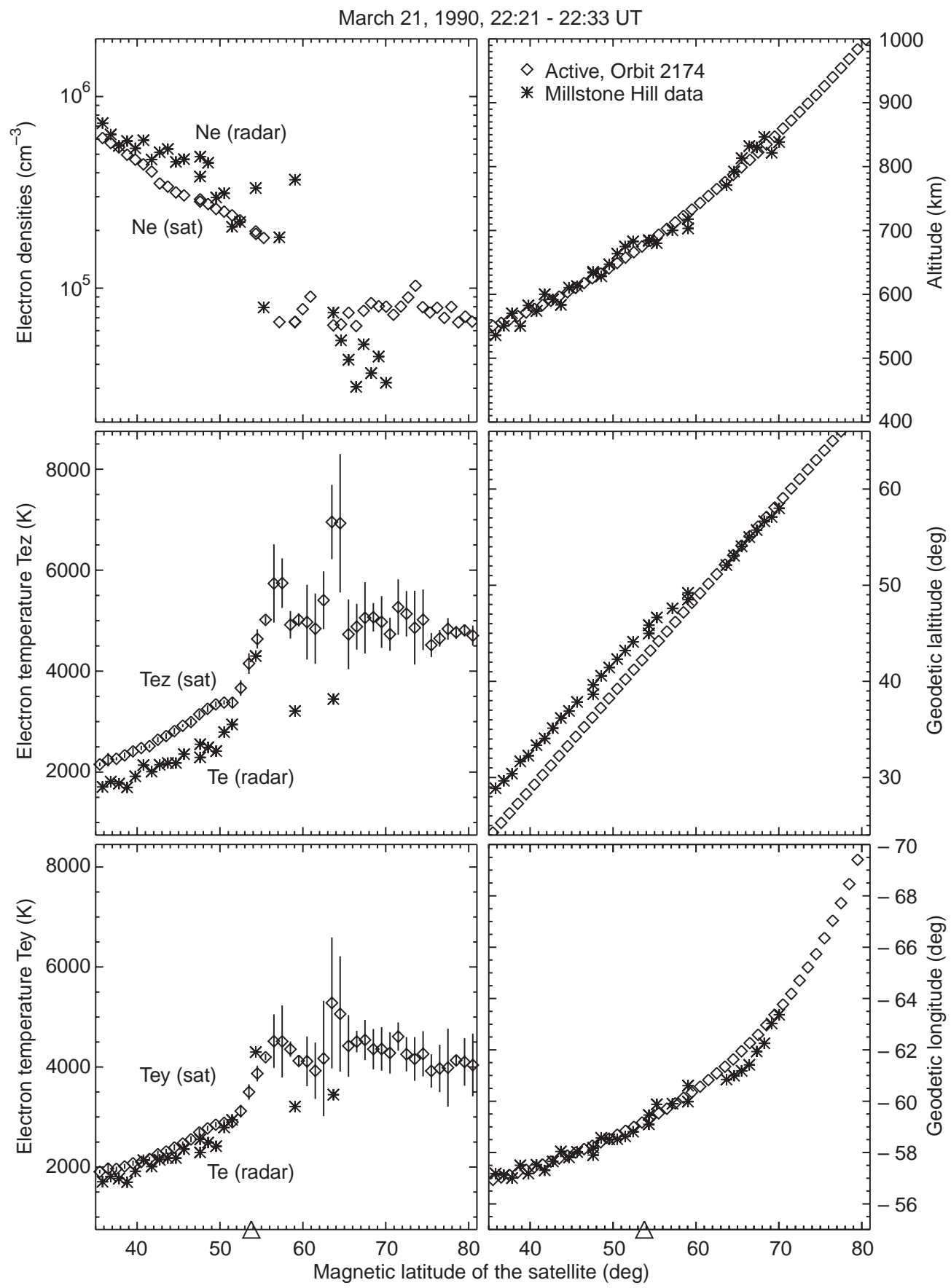

Fig. 9. Direct comparison of the electron density and temperature measurements onboard the Active satellite (diamonds) with the corresponding observations of the Millstone Hill radar (stars) during the overflight 2174 on March 21, 1990. The panels on the right side show as a check the corresponding altitude, latitude and longitude positions of the data points used. The Millstone Hill location is indicated by a triangle at the bottom where possible, shows a good agreement of groundbased and in situ data (see, e.g., Figs. 3 and 9).

\subsection{The SAID event}

There are two different regions of heating within the field of view of the radar during the Active satellite orbit 2174 crossing near Millstone Hill. In both regions, heating caused strong upward-directed ion acceleration processes which are manifested by unusual high molecular ion densities in the upper ionosphere and by depleted electron densities (Fig. 8). The northern region of discrete aurorae is characterised by highly elevated ion and electron temperatures while at subauroral latitudes only $T_{e}$ is enhanced (Figs. 4, 5, and 6).

The ion drift here in the evening sector (about $18 \mathrm{LT}$ ) is westward (sunward) directed with a large peak near the auroral arc. It reaches more than $2000 \mathrm{~m} / \mathrm{s}$. A secondary peak with ion drift velocities of about $750 \mathrm{~m} / \mathrm{s}$ is seen at subauroral latitudes a few degrees northward of Millstone Hill (Figs. 5 and 10). This can be attributed to a subauroral ion drift (SAID) event which is possibly connected with the occurrence of a SAR arc also during this time interval prior to or around sunset.

A recent paper of Foster et al. (1994) discussed the same storm phase of the March 1990 storm, investigating an 8-h interval from dusk till past midnight in the 


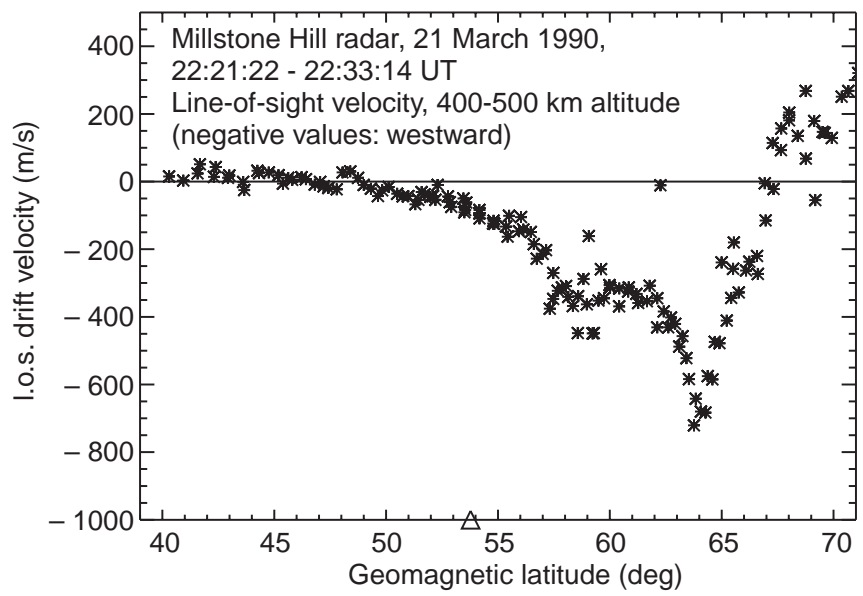

Fig. 10. Line-of-sight drift velocity in the $400-500 \mathrm{~km}$ altitude range as measured by the Millstone Hill radar with the azimuth-elevation scan during the passage of the Active satellite, orbit 2174

North American sector, i.e., a time interval starting about $1.5 \mathrm{~h}$ after the passage of Active presented in detail in the previous section. They showed the development of a long-standing SAR arc event collocated with a SAID event. The optical observations with the Boston University all-sky 630.0-nm imager started after sunset near 00 UT of March 22, 1990, and monitored the two-dimensional position and magnitude of the SAR arc emission. Together with Millstone Hill radar elevation scans they demonstrated that the SAR arc was collocated with a deep, narrow plasma trough, an electron temperature peak of $\sim 3500 \mathrm{~K}$ and a region of enhanced westward plasma convection situated immediately equatorward of the low-latitude extent of plasma sheet particle precipitation. The convection feature was shown to be a SAID event, discussed also in later publications, as, e.g., Foster (1995). At the beginning of their observational interval the subauroral arc was situated at $46^{\circ}$ geodetic latitude $\left(\sim 57^{\circ}\right.$ geomagnetic latitude) northward of Millstone Hill moving then slowly southward across the radar's latitude.

For a further support of our observational basis we looked for data from the DMSP satellite F8 which is located in roughly the same local time sector. There were DMSP F8 crossings $50 \mathrm{~min}$ before and $50 \mathrm{~min}$ after our Active overflight during the azimuth-elevation scan so that we do not have a direct comparison. But the DMSP observation complement our observations quite well as will be shown below.

Figure 12 gives the horizontal ion drift observations of the DMSP F8 satellite near our time interval of interest for three consecutive orbits. The time of the crossings is indicated by tick marks and the horizontal drift velocity perpendicular to the satellite's track is shown by bars perpendicular to the orbital track indicating the direction (approximately westward or eastward) and the amplitude of the drift. This drift pattern agrees with the line-of-sight velocities from the azimuth-elevation scan of the radar in Fig. 10. The large westward directed drift peak(s) of about $2500 \mathrm{~m} / \mathrm{s}$ or more and the shear region northward of it coincides with the auroral arc structure. But there is also a secondary peak at subauroral latitudes near $47^{\circ}-48^{\circ}$ with amplitudes up to $1200 \mathrm{~m} / \mathrm{s}$ which is also seen as a persistent feature in these consecutive orbits of DMSP registrations.

\subsection{Energetic particle precipitations}

The SPE-1 observations comprise energetic particles of ring current energies above about $30 \mathrm{keV}$. The DMSP particle observations (ions and electrons) gives energy spectra from $30 \mathrm{eV}$ to $30 \mathrm{keV}$ and are shown in Fig. 13 for the nearest passage from 23:12 UT to 23:28 UT and
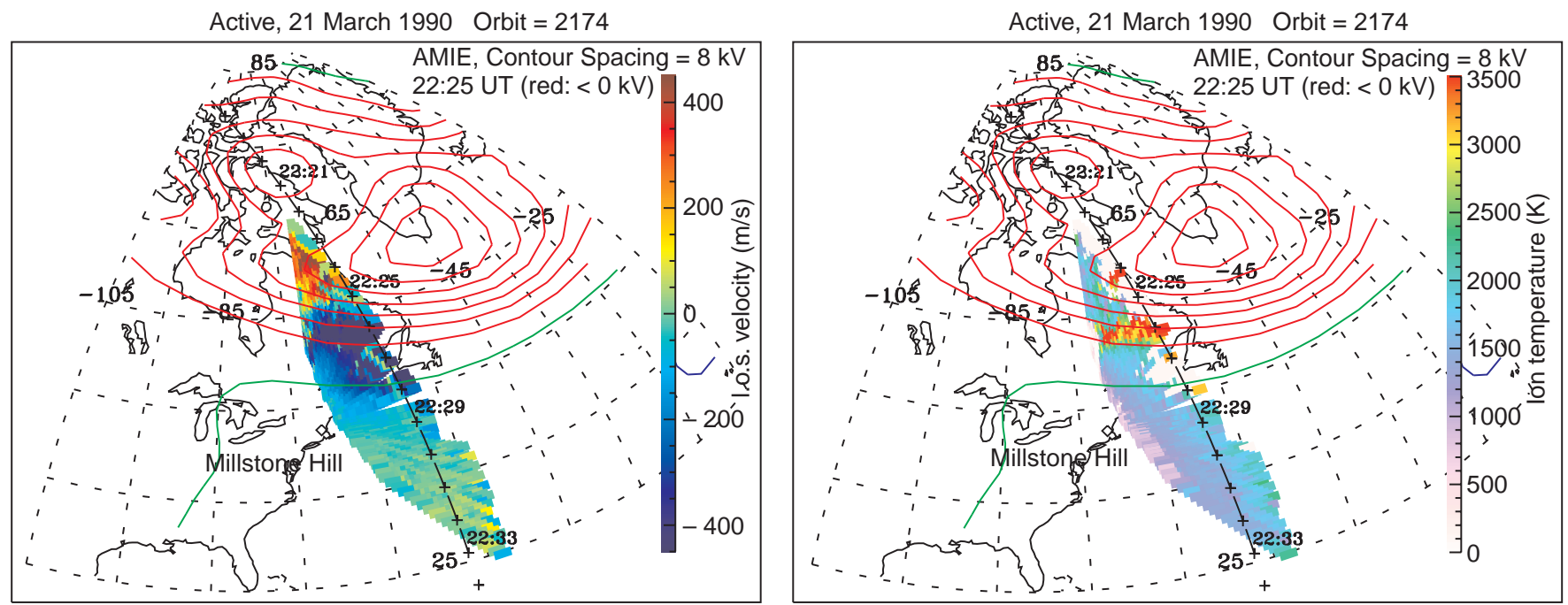

Fig. 11. Line-of-sight drift $\mathbf{a}$ and ion temperature measurements $\mathbf{b}$ of the azimuth-elevation scan of the Millstone Hill radar compared with the AMIE electric field potential pattern for the time moment 22:25 UT. The spacing of the potential contours is $8 \mathrm{kV}$ with the green line as the zero level and the red lines for negative values 
DMSP satellite F08 Horizontal Drift 21-22 March 1990

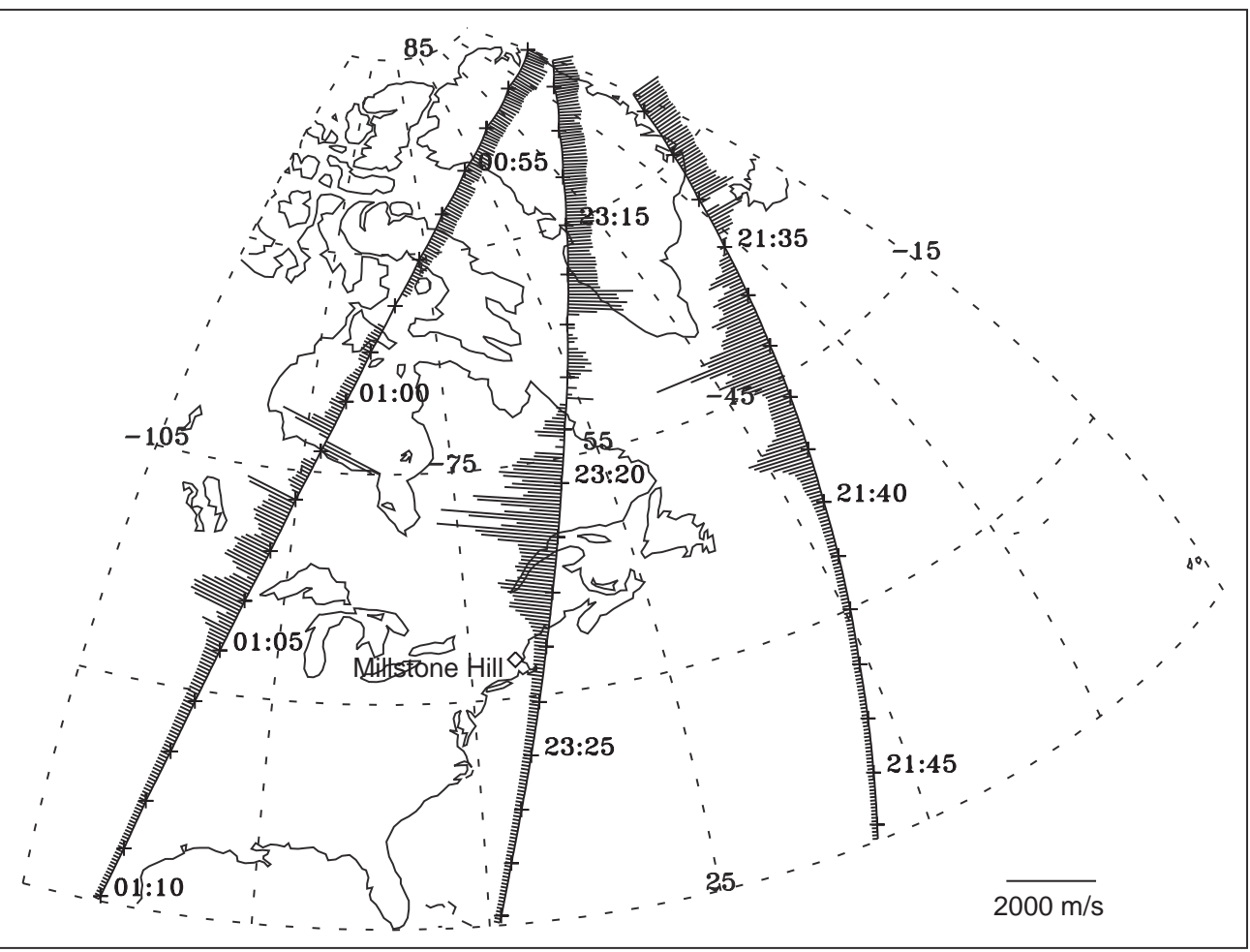

Fig. 12. DMSP F8 satellite measurements of the horizontal ion drift velocities (perpendicular to the satellite's travel path) during a number of passes in the 18 LT meridional plane near the time studied. UT tick marks as shown along the orbital tracks fill, so to say, the "gap" between the thermal plasma observations and the SPE-1 measurements. In the bottom panel the drift observations are repeated which allow us to identify the physically different regions. Strong electron precipitations are seen within the auroral region beginning with the antisunward drift peaks near the shear drift zone at about $74.8^{\circ}$ magnetic latitude (23:16:20 UT) down to $61.7^{\circ}$ (23:21:15 UT). They comprise discrete boundary plasma sheet (BPS) electron precipitation including several "inverted-V" structures and diffuse central plasma sheet (CPS) electron precipitation for a short interval southward of it (near 23:21 UT) with slightly enhanced averaged electron energy of this energy interval.

There are many studies which relate the southernmost boundary of this soft electron precipitation to the position of the (possibly newly formed) plasmapause (see, e.g., Galperin et al., 1997). This boundary coincides in this case, as the DMSP data reveal, also with the equatorward edge of the large-scale convection zone connected with the main auroral drift peaks which show some structuring during the satellite overflight time (splitting into three distinct, intense drift peaks). According to Yeh et al. (1991) the boundary is located at the drift minimum ("M") in between the main auroral and the subauroral peaks and signifies the actual position of the plasmapause $L$-shell. For the exact time of the DMSP overflight it is found at $61.3^{\circ}$ magnetic latitude (Fig. 13) which approximately coincides with the estimation from the time moment of our radar observations which gives a value of $61^{\circ}-62^{\circ}$ (Fig. 10). This latitude corresponds to the southern limit of the strong auroral heating region which is manifested in uplifted molecular ions in the interval from $62.2^{\circ}-71.3^{\circ}$ magnetic latitude (22:24:00-22:26:30 UT, Fig. 8) and the large electron temperature peak at $64.1^{\circ}$ (Fig. 6). One can conclude that this heating region is obviously related to processes adjacent to but outside the plasmapause boundary.

Some (weaker) ion precipitation is also present throughout the auroral region. It intensifies near the equatorward boundary of the auroral arc, extends out into the subauroral region beyond the electron reach in this energy range and becomes somewhat more energetic. The integrated fluxes (uppermost panel in Fig. 13) and the averaged particle energy (second panel) show that the ion fluxes penetrate down to the secondary drift maximum and have their largest energies even there between the auroral drift maximum and the SAID maximum. This behaviour of the energetic ions was shown in Fig. 7 to proceed to higher energies up to a few hundred $\mathrm{keV}$. The ion spectra there showed intense ion fluxes with some dispersion just between these two marks from 22:26 UT to 22:28 UT.

It is this difference in the larger penetration depth of the energetic ions with respect to the electrons which produces the intense polarisation electric field at subauroral latitudes known as the SAID event.

On the other hand, the energetic spectra in Fig. 7 of "trapped" (2nd panel) and precipitating electrons (panels 1 and 3) starting a little more southward and extending further equatorward are not seen in the DMSP F8 data (Fig. 13). Considering the colour-coded scales on the right hand side of Figs. 7 and 13 it is clear that the electron fluxes at higher energies of the SPE-1 registrations are at least two orders of magnitude less 


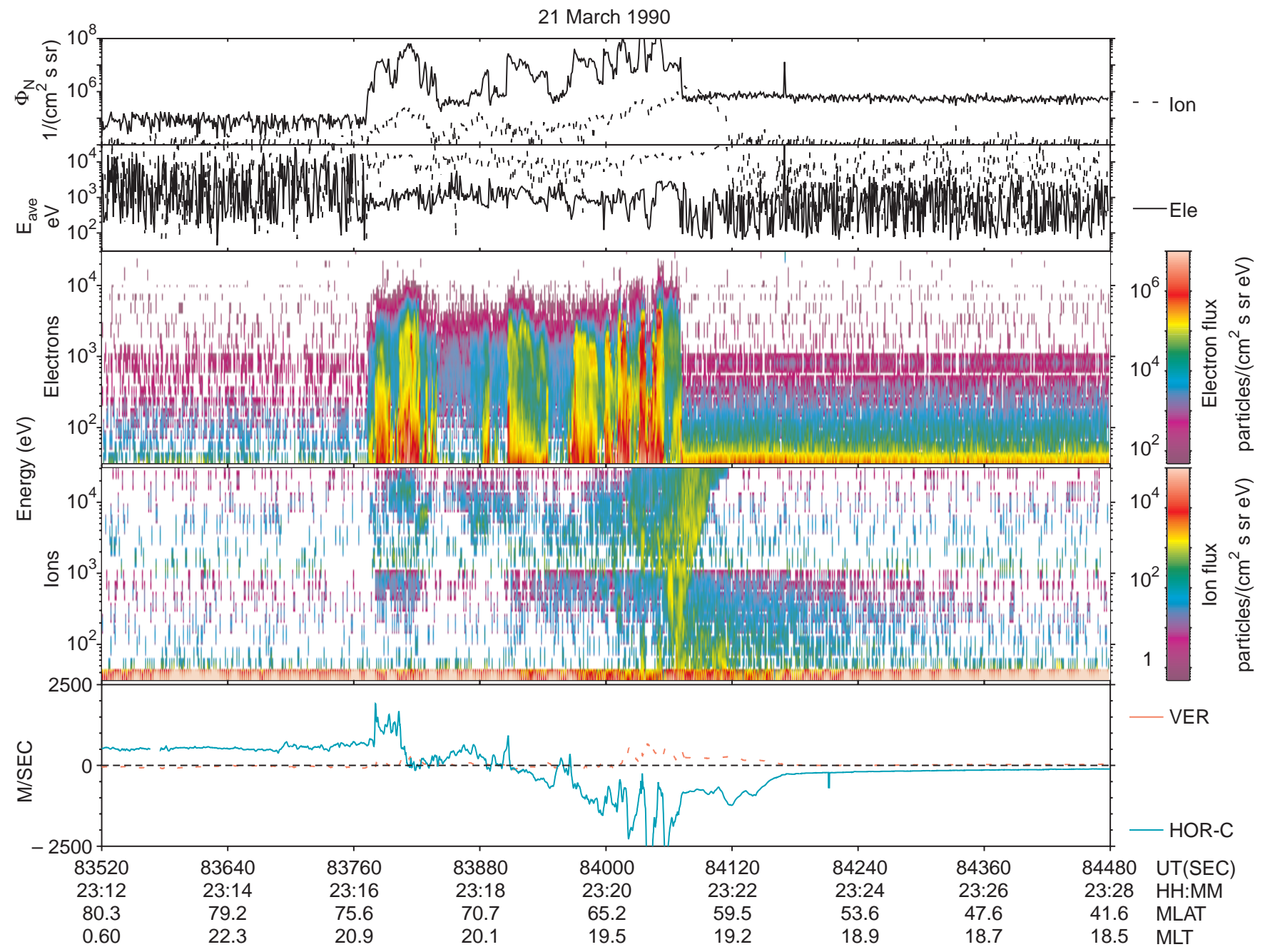

Fig. 13. Data from DMSP F8 overflight near Millstone Hill on March 21, 1990, 23:12-23:28 UT. The two upper panels show the integrated $(30 \mathrm{eV}-30 \mathrm{keV})$ electron and ion fluxes $\Phi_{N}$ and their average energy $E_{\text {ave }}(\mathrm{eV})$. Then the spectrogram of precipitating electrons ( $3 \mathrm{rd}$ panel) and ions (4th panel) are given as false-colour-coded flux values. The bottom panel gives the components of the thermal ion bulk flow

perpendicular to the satellite path in the horizontal plane (blue line) and the vertical plane (red dots). Several large auroral drift velocity peaks of more than $2500 \mathrm{~m} / \mathrm{s}$ near 23:21 UT (about 62.5 MLAT) and the SAID peak of about $1200 \mathrm{~m} / \mathrm{s}$ near 23:22 UT (about 59.5 MLAT) are clearly seen

intense than the weakest fluxes of Fig. 13 with $10^{5}$ particles $/\left(\mathrm{keV} \mathrm{cm}^{2} \mathrm{~s} \mathrm{sr}\right)$. The maximal ion fluxes in Fig. 7 are achieved at 22:26:50 UT or $61.0^{\circ}$ magnetic latitude in the lowest energy channel $(55.2-63.9 \mathrm{keV})$ with $6 \times 10^{3}$ particles $/\left(\mathrm{keV} \mathrm{cm}^{2} \mathrm{~s} \mathrm{sr}\right)$ while Fig. 13 shows $10^{5}-10^{6}$ particles $/\left(\mathrm{keV} \mathrm{cm}^{2} \mathrm{~s} \mathrm{sr}\right)$ of ion fluxes at the upper limit of $30 \mathrm{keV}$ in the same topological region. Additionally, there is a noticable ion population with energies $<1 \mathrm{keV}$ in the same region, i.e., equatorward of the low-energy electron precipitation boundary.

\subsection{Dynamical processes at the newly settled plasmapause}

Cornwall et al. (1970) first suggested that the interaction between ring current ions and ion cyclotron waves (ICW) at the plasmapause density gradient serves as an important ring current loss process and as a heating mechanism for the thermal electron gas just inside and along the plasmapause. Cornwall et al. (1971) investigated the Landau damping of ICW's as a plausible energy transfer mechanism from the ring current to the thermal electrons. Kozyra et al. (1987) studied in detail the role of Coulomb collisions as a major heating mechanism of the electron gas and showed them to be sufficient for $\mathrm{O}^{+}$ions but too small for ring current protons alone. All these processes which can explain the occurence of highly enhanced electron temperatures at $F_{2}$-layer heights near the plasmapause position and which result in SAR arcs were studied in detail theoretically (see, e.g., Kozyra et al., 1987) and also statistically (e.g., Kozyra et al., 1986; Brace et al., 1988). Nevertheless, many questions remain unresolved in this regard and model studies of individual storm events as that of Kozyra et al. (1997) for the November 1993 storm will help to clarify the complex interactions.

In a recent paper of Titova et al. (1998) energetic electron precipitation with ring current energies in the 
evening sector accompanied by a sharp increase in trapped energetic electron flux observed at the lowEarth orbit of the NOAA satellites were analysed. According to their report, these particle precipitations occur mainly in the evening sector near the probable position of the plasmapause L-shell and only during the recovery phase of magnetic storms. They are accompanied by ring current ion precipitations at a slightly poleward shifted latitude as it is observed in our case (Fig. 7). Titova et al. (1998) call it "cliff"-like due to the sharpness of the increase of the trapped energetic electron flux at one side and report about burst-like spikes of the precipitating fluxes. The same energetic electron behaviour is observed by the three detectors of the SPE-1 device onboard Active during its overflight above the radar. There is a single large spike near 22:26:35 UT $\left(61.9^{\circ}\right)$ and several other near 22:28 UT or $56.6^{\circ}$ magnetic latitude (Fig. 7, panels 1 and 3). This is near the secondary, subauroral drift peak (SAID) and at the same time just at the location of the subauroral electron temperature maximum (Fig. 6) with peak temperatures of more than $6000 \mathrm{~K}$ at the altitude of the satellite $(700 \mathrm{~km})$. The temperature at the altitude of a possible SAR arc emission maximum (about $450 \mathrm{~km}$ ) is estimated by the radar measurements to about $3500 \mathrm{~K}$. Together with a precipitation component of low-energetic electrons (as suggested by Slater et al., 1987) or ions (Mendillo et al., 1987) this is sufficient for an excitation of SAR arc emissions although they cannot be observed during day-light. The simultaneous sharp increase in both trapped and precipitating electron fluxes of ring current energies can be the result of significant pitch-angle isotropisation of drifting electrons caused by their interaction via the cyclotron instability at the background of increased thermal plasma density as it is present at the plasmapause or at detached regions of enhanced thermal plasma density. Theoretical explanations for this process are given by Trakhtengerts et al. (1996) and Pasmanik et al. (1998).

According to Carpenter and Anderson (1992), the plasmapause position outside the plasmaspheric bulge region, i.e., for $00-15 \mathrm{LT}$, can be related to the maximal $K p$-value of the previous $24 \mathrm{~h}$. For the time moment under study on 21 March 1990 this would result in a value of $L=2.24$ which is really confirmed for the morning side orbits of the Active satellite on this day as was shown by Jiřiček et al. (1996). For the dusk side, on the other hand, these authors identify the formation of a plasmaspheric bulge even under relatively high activity. From the position of the equatorward edge of the light ion trough and of the subauroral $T_{e}$ peak they deduce the plasmapause location at dusk for orbit 2174 on 21 March 1990 above North America to $L \sim 3.4$ $\left(\operatorname{INVLAT}=57^{\circ}\right)$. This is approximately confirmed by the energetic particle measurements presented in this study although the structuring of the outer plasmasphere seems to be richer. The occurrence of several burst-like spikes of precipitating energetic electrons indicates the presence of "steps" and/or "detached regions". The latter is very likely for the isolated peak near $61.9^{\circ}$ magnetic latitude $(L=4.5)$. However, fossil troughs from former storm intensifications and newly formed troughs may also occur owing to the action of the strong SAID electric field as was demonstrated in a modelling study by Ober et al. (1997) seem to be plausible. One can localise such structures at $56.6^{\circ}$ magnetic latitude $(L=3.3)$.

Auroral and subauroral heating and transport processes lead also to disturbed regions of neutral gas distributions. For the present interval this was investigated by Mikhailov and Förster (1997). The disturbance region is characterised by enhanced densities of neutral molecular species with a relatively sharp boundary toward mid-latitudes.

This behaviour is insufficiently represented by the usually used empirical MSIS neutral gas model. During the period of our study, this boundary was probably just northward of Millstone Hill as indicated by the steplike decrease in $N_{e}$ at about $55^{\circ}$ geomagnetic latitude and moved over the radar station in the course of the night. From model studies with an iterative optimisation code the daytime values of the neutral gas parameters were estimated using measured Millstone Hill radar profiles by Mikhailov and Förster (1997). A numerical model study of the storm period should take into account the specified neutral gas distributions. Such a numerical study is planned in a subsequent paper for this event based on the rich observational material outlined here.

\section{Conclusions}

During a nearby passage of the Active satellite above the Millstone Hill radar on 21 March 1990, at local sunset times correlative observations of the satellite probes and a special azimuth-elevation scan of the radar were carried out. In this way, simultaneous measurements of upper ionospheric parameters in nearly the same spatial volume were performed which took place, by chance, during the extented recovery phase of the intensively studied CEDAR storm interval of March 1990. Direct comparisons of radar data and in-situ satellite measurements have only been carried out in quite rare cases. Here, the coincidence of co-ordinated measurements and active ionospheric-magnetospheric processes during an extended storm recovery phase presents an unique occasion resulting in a very valuable data set.

The measurements show very good agreement for spatial and temporal intervals where they can be directly compared. The radar and different satellite observations complement each other and give therefore a comprehensive picture of the processes during this storm phase.

In a recent paper of Foster et al. (1994) the same recovery phase beginning at a precise local time about $1.5 \mathrm{~h}$ later was analysed by radar and optical measurements. They concluded that there a close relationship exists among the location of the SAR arc observed optically and the SAID event registrated by the radar observations with its isolated subauroral secondary westward drift maximum, the electron temperature peak and the narrow trough. These structures persisted for the course of the observational interval $(8 \mathrm{~h})$. From the 
observations presented in this study it is clear that these SAID/SAR arc event structures were already present before sunset, at least $1.5 \mathrm{~h}$ earlier. At that time they were located a few degrees northward of Millstone Hill moving then slowly toward lower latitudes.

The SAID electric field is caused by the penetration of energetic ions with energies between about $1 \mathrm{keV}$ and $100 \mathrm{keV}$ into the outer plasmasphere and the resulting charge separation or polarisation effect. The plasmapause position at this time moment can be located to magnetic latitudes at or less $61.9^{\circ}(L \sim 4.5)$ revealing the existence of a dusk side bulge during this storm phase. At the same time one can state that the outer parts of the plasmasphere from $L=4.5$ to at least $L=3.3$ are very structured with detached plasma regions and fossil and/or newly formed troughs near the latitude of the SAID maximum at this local time moment $\left(58^{\circ}-59^{\circ}\right.$ magnetic latitude).

The auroral heating processes as well as the subauroral region subjected to the SAID event give rise to an intense uplifting of molecular ions up to the upper ionosphere as registrated by the satellite probe HAM-5 at altitudes between 700 and $870 \mathrm{~km}$. This points to strong heating or acceleration processes which are different in nature for the auroral region on one side and for the SAID/SAR arc event region on the other side. These processes also lead to a strong upwelling and redistribution of the neutral gas constituents.

Acknowledgements. We are grateful to F. J. Rich (Air Force Research Laboratory, Hanscom AFB, Massachusetts) for providing DMSP F8 and F9 satellite data and to J. R. Taylor (Department of Physics and Astronomy, University of Leicester, Leicester, UK) for fruitful discussions and for providing the AMIE convection pattern files of the CEDAR March 1990 storm campaign. The Millstone Hill facility is supported by the National Science Foundation through a Co-operative Agreement with the Massachusetts Institute of Technology. The Active/Millstone experiments were supported by NASA Grant NAG-5-1343 to MIT. One of the authors (KK) wishes to acknowledge the support of the Slovak Grant Agency VEGA under grant 5137. The technical assistance of Mrs. Jana Stetiarova (Institute of Experimental Physics, Kosice) for data processing of the energetic particle flux data is gratefully acknowledged.

Topical Editor D. Alcaydé thanks M. Codrescu and V. Trakhtengerts for their help in evaluating this paper.

\section{References}

Afonin, V. V., K. V. Grechnev, V. A. Ershova, O. Z. Roste, N. F. Smirnova, J. A. Shultschishin, and J. Smilauer, The ion composition and ionosphere temperatures in the maximum of $22^{\text {nd }}$ cycle of solar activity as measured on board "Intercosmos24” (project Active) satellite, Kosm. Issled., 32, 82-94, 1994, (in Russian).

Anderson, P. C., R. A. Heelis, and W. B. Hanson, The ionospheric signatures of rapid subauroral ion drifts, J. Geophys. Res., 96, 5785-5792, 1991

Brace, L. H., C. R. Chappell, M. O. Chandler, R. H. Comfort, J. L. Horwitz, and W. R. Hoegy, F region electron temperature signatures of the plasmapause based on Dynamics Explorer 1 and 2 measurements, J. Geophys. Res., 93, 1896, 1988.

Buonsanto, M., J. Foster, and D. Sipler, Observations from Millstone Hill during the geomagnetic disturbances of March and April 1990, J. Geophys. Res., 97, 1225-1243, 1992.
Carpenter, D. L., and R. R. Anderson, The ISEE/whistler model of equatorial electron density in the magnetosphere, J. Geophys. Res., 97, 1097, 1992.

Cornwall, J. M., F. V. Coroniti, and R. M. Thorne, Turbulent loss of ring current protons, J. Geophys. Res., 75, 4699, 1970.

Cornwall, J. M., F. V. Coroniti, and R. M. Thorne, Unified theory of SAR arc formation at the plasmapause, J. Geophys. Res., 76, 4428-4445, 1971.

Förster, M., N. Jakowski, A. Best, and J. Smilauer, Plasmaspheric response to the geomagnetic storm period March 20-23, 1990, observed by the Activny (Magion-2) satellite, Can. J. Phys., 70, 569-574, 1992.

Foster, J. C., Radar observations of magnetosphere-ionosphere coupling at mid and high latitudes, J. Geomagn. Geoelectr., 47, 801-812, 1995.

Foster, J. C., M. J. Buonsanto, M. Mendillo, D. Nottingham, F. J. Rich, and W. Denig, Coordinated stable auroral red arc observations: relationship to plasma convection, J. Geophys. Res., 99, 11 429-11 439, 1994.

Galperin, Y. I., V. N. Ponomarev, and A. G. Zosimova, Direct measurements of ion drift velocity in the upper ionosphere during a magnetic storm, 2. Results of measurements during November 3, 1967, magnetic storm (in Russian), Kosm. Issled., 11, 283-292, 1973.

Galperin, Y. I., V. N. Ponomarev, and A. G. Zosimova, Plasma convection in the polar ionosphere, Ann. Geophysicae, 30, 1-7, 1974.

Galperin, Y. I., V. S. Soloviev, K. Torkar, J. C. Foster, and M. V. Veselov, Predicting plasmaspheric radial density profiles, $J$. Geophys. Res., 102(A2), 2079-2091, 1997.

Green, J. L., J. H. Waite, Jr., C. R. Chappell, M. O. Chandler, J. R. Doupnik, P. G. Richards, R. Heelis, S. D. Shawhan, and L. H. Brace, Observations of ionospheric magnetospheric coupling: DE and Chatanika coincidences, J. Geophys. Res., 91, 5803$5815,1986$.

Jiřiček, F., J. Smilauer, P. Třiska, and L. Třiskova, Response of the outer ionosphere to the magnetic storm of 20-22 March 1990, J. Atmos. Terr. Phys., 58, 855-865, 1996.

Kozyra, J. U., L. H. Brace, T. E. Cravens, and A. F. Nagy, A statistical study of the subauroral electron temperature enhancement using Dynamics Explorer 2 Langmuir probe observations, J. Geophys. Res., 91, 11, 270, 1986.

Kozyra, J. U., E. G. Shelley, R. H. Comfort, L. H. Brace, T. E. Cravens, and A. G. Nagy, The role of ring current $\mathrm{O}^{+}$in the formation of stable auroral red arcs, J. Geophys. Res., 92, 7487$7502,1987$.

Kozyra, J. U., V. K. Jordanova, R. B. Horne, and R. M. Thorne, Modeling of the contribution of electromagnetic ion cyclotron (EMIC) waves to stormtime ring current erosion, in Magnetic storms, Ed. B. T. Tsurutani, W. D. Gonzalez, Y. Kamide, and J. K. Arballo, vol 98 of Geophysical Monograph, pp. 187-202, American Geophysical Union, 1997.

Kudela, K., J. Matisin, F. K. Shuiskaya, O. S. Akentieva, T. V. Romantsova, and D. Venkatesan, Inner zone electron peaks observed by the 'Active' satellite, J. Geophys. Res., 97(A6), 8681-8683, 1992.

Mendillo, M., J. Baumgardner, J. Aarons, J. Foster, and J. Klobuchar, Ground-based imaging of detailed arcs, ripples in the diffuse aurora, and patches of 6300 a emission, Ann. Geophysicae, 5A, 543-550, 1987.

Mikhailov, A. V., and M. Förster, Day-to-day thermosphere parameter variation as deduced from Millstone Hill incoherent scatter radar observations during March 16-22, 1990 magnetic storm period, Ann. Geophysicae, 15, 1429-1438, 1997.

Mikhailov, A. V., and K. Schlegel, Self-consistent modelling of the daytime electron density profile in the ionospheric F-region, Ann. Geophysicae, 15(3), 314-326, 1997.

Ober, D. M., J. L. Horwitz, and D. L. Gallagher, Formation of density troughs embedded in the outer plasmasphere by subauroral ion drift events, J. Geophys. Res., 102(A7), 14 595$14602,1997$. 
Pasmanik, D. L., V. Y. Trakhtengerts, A. G. Demekhov, A. A. Lyubchich, E. E. Titova, T. A. Yahnina, M. J. Rycroft, J. Manninen, and T. Turunen, A quantitative model for cyclotron wave-particle interactions at the plasmapause, Ann. Geophysicae, 16, 322- 330, 1998.

Richards, P. G., D. G. Torr, M. J. Buonsanto, and D. Sipler, Ionospheric effects of the March 1990 magnetic storm: comparison of theory and measurement, J. Geophys. Res., 99, 23 359-23, 365, 1994.

Richmond, A. D., Assimilative mapping of ionospheric electrodynamics, Adv. Space Res., 12(6), 59-68, 1992.

Richmond, A. D., and Y. Kamide, Mapping electrodynamic features of the high-latitude ionosphere from localized observations: technique, J. Geophys. Res., 93, 5741-5759, 1988.

Rodger, A. S., R. J. Moffett, and S. Quegan, The role of the ion drift in the formation of ionization troughs in the mid- and high-latitude ionosphere: a review, J. Atmos. Terr. Phys., 54, 130, 1992.

Slater, D. W., C. Gurgilio, J. U. Kozyra, E. W. Klecker, and J. D. Winningham, A possible energy source to power stable auroral red arcs: precipitating electrons, J. Geophys. Res., 92, 45434552, 1987.

Smiddy, M., M. C. Kelley, W. J. Burke, F. J. Rich, E. Sagalyn, B. Shuman, R. Hays, and S. Lai, Intense poleward directed electric fields near the ionospheric projection of the plasmapause, Geophys. Res. Lett., 4, 543-546, 1977.
Smilauer, J., and K. Kubat, Ionospheric electron temperature measurements using a radio-frequency probe, Trav. Inst. Geophys. Acad. Tchecoslov-Sci., 21, 457-467, 1973.

Taylor, J. R., T. K. Yeoman, M. Lester, M. J. Buonsanto, J. L. Scali, J. M. Ruohoniemi, and J. D. Kelly, Ionospheric convection during the magnetic storm of activity on 20-21 march 1990, Ann. Geophysicae, 12, 1174-1191, 1994.

Taylor, J. R., T. K. Yeoman, M. Lester, B. A. Emery, and D. J. Knipp, Variations in the polar cap area during intervals of substorm activity on 20-21 march 1990 deduced from AMIE convection pattern, Ann. Geophysicae, 14, 879-887, 1996.

Titova, E. E., et al., Strong localized variations of the low-altitude energetic electron fluxes in the evening sector near the plasmapause, Ann. Geophysicae, 16, 25-33, 1998.

Trakhtengerts, V. Y., A. A. Lyubchich, A. G. Demekhov, T. A. Yahnina, E. E. Titova, M. J. Rycroft, J. Manninen, and T. Turunen, Cyclotron model for quasi-steady precipitation of energetic electrons at the plasmapause, in Proc. XIX Seminar on Auroral Phenomena, pp. 73-76, Apatity, Russia, PGI, 1996.

Tr̆iska, P., F. Jiřiček, V. Velický, and J. Vojta, A subsatellite for mother-daughter Active space experiments, Adv. Space Res., 10, (7)165-(7)168, 1990.

Yeh, H.-C., J. C. Foster, F. J. Rich, and W. Swider, Storm time electric field penetration observed at mid-latitude, J. Geophys. Res., 96, 5707-5721, 1991. 